\title{
«OPINIÓN PÚBLICA LIBRE»Y MEDIOS DE COMUNICACIÓN SOCIAL EN LA ARGUMENTACIÓN JURÍDICA DEL TRIBUNAL CONSTITUCIONAL ESPAÑOL
}

«The Court of Public Opinion, open day and night, is to lay down for everything all the time. It is not workable. And when you consider the nature of news, it is not even thinkable».

Walter Lippman

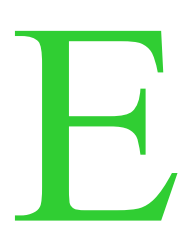

1 concepto de opinión pública, o de «opinión pública libre» (en adelante O.P. y O.P.L.) forma parte del discurso jurídico constitucional del Estado democrático. Aunque no aparezca en el texto constitucional, dicho concepto es utilizado frecuentemente, con un valor normativo, en la argumentación de las sentencias y resoluciones de los tribunales constitucionales. También el Tribunal Constitucional español ha recurrido a él en diversas ocasiones, sobre todo como base legitimadora capaz de proyectar determinadas condiciones para la regulación jurídica de los medios de comunicación de masas, especialmente de la televisión. El T.C. se ha servido de él para justificar una organización de los medios independiente del poder y pluralista, requisito que estima indispensable para la libre formación de la O.P. Una O.P.L. vendría exigida por el paradigma de legitimidad del Estado democrático, puesto que, sin ella, quedarían vaciados de contenido otros derechos y garantías constitucionales, y su ejercicio no respondería al sentido democrático con el que esos derechos y garantías han sido dotados.

Este trabajo pretende analizar la estrategia argumentativa que ha desarrollado el alto tribunal a partir del concepto de O.P.L. Pretende mostrar las implicaciones filosófico-políticas que hay en el uso de ese tópico, y cuestionar la consistencia que tiene su utilización como fundamento de un discurso tendente a la legitimación democrática del 
Estado. Es un trabajo, por tanto, de crítica de la ideología jurídica, porque, adelantando conclusiones, el que suscribe está convencido del carácter mítico que tiene la opinión pública (libre) en una sociedad dominada por los medios de masas, y especialmente de la televisión.

Para ello voy a exponer, en primer lugar, brevemente las sentencias del T.C. en las que aparece el concepto de O.P.L., respetando la coherencia interna de la argumentación y señalando las líneas fundamentales que jalonan el discurso jurídico del Tribunal (I). En segundo lugar, voy a proceder a explicar el alcance normativo que el concepto de O.P. tiene desde el punto de vista de la legitimidad democrática del Estado (II). Finalmente, me voy a referir a los obstáculos que desde los medios de comunicación de masas pueden surgir para la formación de una O.P.L., y que, incluso a pesar de todas las precauciones jurídico-políticas, suponen un desmentido a las pretensiones legitimadoras del discurso jurídico acerca de la O.P. (III).

\section{Las sentencias del Tribunal Constitucional sobre la opinión pública y los medios}

Los argumentos del T.C. se inscriben en la tradición filosófico jurídica del pensamiento liberal, completados con las aportaciones y correcciones que como consecuencia de la vigencia histórica del Estado social han sido realizadas a dicha tradición. El punto de partida de tales argumentos lo constituye sin duda la Constitución española de 1978, que en su artículo 20.1 apartado a) garantiza el derecho «a expresar y difundir libremente los pensamientos, ideas y opiniones mediante la palabra, el escrito o cualquier otro medio de reproducción», y en su apartado d) «a comunicar o recibir libremente información veraz por cualquier medio de difusión».

En su primera sentencia sobre el tema, pronunciada el 16 de marzo de 1981 (STC 6/1981), el T.C. esboza las líneas básicas configuradoras de la interpretación de los derechos y libertades del artículo $20 \mathrm{CE}$, que serán confirmadas y desarrolladas en sentencias posteriores ${ }^{1}$. En el contexto de esta interpretación, el T.C. recurre al concepto de «comunicación pública libre» como finalidad objetiva de

${ }^{1}$ Se trata en esta sentencia de resolver un recurso de amparo interpuesto por unos periodistas contra las sentencias del Tribunal Supremo y de la Audiencia Nacional que confirmaban un acuerdo del Consejo de Dirección del Organismo Autónomo «Medios de Comunicación Social del Estado», por el que suspendió la publicación de dos diarios de San Sebastián. El recurso es desestimado, pero de los razonamientos del T.C. se desprenden importantes conclusiones acerca del alcance sociopolítico de las libertades de expresión e información. 
las libertades de expresión e información, y con este concepto, las garantías del proceso democrático de formación de la voluntad política entran a formar parte del sentido de esas libertades: «El artículo $20 \mathrm{CE}$, en sus distintos apartados», dice el Tribunal, «garantiza el mantenimiento de una comunicación pública libre, sin la cual quedarían vaciados de contenido real otros derechos que la Constitución consagra, reducidas a formas hueras las instituciones representativas y absolutamente falseado el principio de legitimidad democrática que enuncia el artículo 1, apartado 2 de la Constitución, y que es la base de toda nuestra ordenación jurídico-política. La preservación de esta comunicación pública libre exige la garantía a ciertos derechos fundamentales, «pero también una especial consideración a los medios que aseguran la comunicación social (...)» (F.J. 3. $\left.{ }^{\circ}\right)$.

Ya desde esta primera sentencia, la argumentación del T.C. enfoca los derechos subjetivos a la libertad de expresión e información desde el punto de vista de su función política objetiva. A partir de aquí, el ejercicio de tales derechos podrá experimentar los condicionamientos que se estimen necesarios para asegurar que la mencionada función política no quede desvirtuada. Consecuentemente, los poderes públicos están legitimados para adoptar las medidas que estimen necesarias a fin de preservar la libertad de la comunicación pública, sobre todo por lo que respecta a la organización jurídica de los medios.

Una segunda sentencia del T.C., de fecha 31 de marzo de 1982 (STC/1982), reitera y amplía los argumentos utilizados en la primera. Se puede decir que ésta es la sentencia más importante que ha pronunciado el T.C. sobre los medios de comunicación, en la que de una forma más explícita insiste en la relación entre la O.P., la democracia y los medios²:

1. Según el Tribunal, el artículo 20.1 CE protege ante todo un derecho de libertad, que se traduce en la ausencia de interferencias o intromisiones de las autoridades estatales en el proceso de comunicación.

${ }^{2}$ En esta ocasión el T. C. se pronuncia sobre la posibilidad de organizar la televisión privada enEspaña. Según la ley, la radio y la televisión son consideradas como «servicios públicos esenciales cuya titularidad corresponde al Estado» (art. $1^{\circ}, 2$ de la Ley 4/1980, de 10 de enero, del Estatuto de la Radio y la Televisión), y la gestión de la televisión está en ese momento monopolizada por el ente público RTVE. Al T. C. llega un recurso de amparo en el que se solicita el reconocimiento del derecho a gestionar, por parte de una compañía privada, el servicio público de la televisión para todo el ámbito nacional. El Tribunal desestima el recurso, y entre sus argumentos ocupa un lugar destacado la necesidad de preservar el pluralismo comunicativo. 
Pero también significa «el reconocimiento y la garantía de una institución política fundamental, que es la opinión pública libre, indisolublemente ligada con el pluralismo político, que es un valor fundamental y un requisito del funcionamiento del Estado democrático». Como derecho de libertad común a todos los ciudadanos, «comprende en principio el derecho a crear los medios materiales a través de los cuales la difusión se hace posible». Pero este derecho «presenta indudables límites», entre los cuales se encuentra «la necesidad de no impedir un igual ejercicio de los mismos derechos por los demás ciudadanos». La escasez natural o tecnológica de los bienes que se utilizan como medio de reproducción determina una tendencia oligopolística que es preciso evitar, e igualmente es necesario articular jurídicamente el goce de tales bienes y resolver los problemas técnicos que plantea su utilización (F. J. $3^{\circ}{ }^{\circ}$ ).

2. «La configuración de la televisión como servicio público, aunque no sea una afirmación necesaria en nuestro orden jurídico-político, se encuentra dentro de los poderes del legislador». Tal configuración, establecida en el artículo $1 .^{\circ}, 2$, de la Ley 4/1980, de 10 de enero, se fundamenta en la concepción que el legislador mantiene respecto a la radio y la televisión, y que manifiesta en el preámbulo de dicha ley: la radio y la televisión «son un vehículo esencial de información y de participación política de los ciudadanos, de formación de la opinión pública, de cooperación con el sistema educativo, de difusión de la cultura española y de sus nacionalidades y regiones y de medio de contribución para que la libertad y la igualdad sean efectivas». Ahora bien, «adoptar el sistema de gestión indirecta del servicio público requiere una decisión del legislador y un desarrollo legislativo que este Tribunal no puede suplir». (F. J. $4 .^{\circ}$ y $5 .^{\circ}$ ).

3. ${ }^{\circ}$ La televisión privada no está impuesta por el artículo $20 \mathrm{CE}$, ni se deriva necesariamente de él. Tampoco está constitucionalmente impedida. «Su implantación no es una exigencia jurídico-constitucional, sino una decisión política que puede adoptarse, dentro del marco de la Constitución, por la vía de una Ley orgánica en la medida en que afecta al desarrollo de alguno de los derechos constitucionalizados en el artículo 20 (artículo $81 \mathrm{CE}$ ) y siempre que, al organizarla, se respeten los principios de libertad, igualdad y pluralismo, (...) sea como factores resultantes de las relaciones del conjunto, sea como factores operantes dentro de cada uno de los establecimientos que actúen en el medio, (...) porque tanto se viola la comunicación libre al ponerle obstáculos desde el poder como el ponerle obstáculos desde los propios medios de difusión» (F. J. 6. ${ }^{\circ}$ ).

Como vemos, esta sentencia insiste en la funcionalidad objetiva del derecho a la libertad de expresión e información. Este no se puede 
considerar sólo como un derecho que protege un interés meramente individual, y que se traduciría en la abstención del Estado de cualquier regulación o actividad que pudiera perturbarlo, sino que hay que entenderlo también como garantía de una institución política fundamental, como es la «opinión pública libre». Es la primera vez que el T.C. utiliza literalmente este tópico, que volverá a repetir en multitud de sentencias posteriores. La O.P.L., indisolublemente ligada al pluralismo político, valor fundamental del Estado democrático, sirve como argumento orientado a limitar el ejercicio del derecho a la libertad de expresión e información, o mejor dicho, la libre iniciativa a la hora de crear los medios materiales que lo hacen posible. El derecho no puede ser absoluto, sino relativo: queda relativizado en aras del pluralismo político.

Nuestro T. C. sigue una lógica que en principio, es coherente con la ideología del individualismo liberal: el ejercicio del derecho de uno no puede impedir el ejercicio de los derechos de los demás. El derecho no se puede convertir en privilegio. Si la libre formación de la O. P. queda obstaculizada por el hecho de que no todos pueden jurídicamente contribuir a ella, entonces se imponen ciertas restricciones.

Pero no es solamente la limitación natural de los medios materiales de difusión (las ondas electromagnéticas) lo que exige una intervención reguladora del Estado, sino consideraciones de interés general, es decir, la conciencia de que el libre juego de las fuerzas sociales no conduce necesariamente al fin que se considera deseable. Es una lógica distinta, la lógica del Estado social, la que aquí se introduce y da sentido a las argumentaciones del Tribunal Constitucional.

Por eso, la limitación o relativización del derecho llega hasta el punto de su transformación en servicio público. Este es también el caso de la mayoría de los países democráticos, sobre todo europeos, cuyos ordenamientos jurídicos reservaron en su momento al Estado la actividad radiotelevisiva, dadas las condiciones no sólo tecnológicas (la aludida escasez de frecuencias), sino también económicas (necesidad de invertir grandes capitales) y sociológicas (amplitud de los efectos) de dicha actividad. El origen de la institución jurídica del servicio público para la radiotelevisión comienza en el mismo momento en que se inicia la actividad radiofónica, tanto por razones democráticas, dadas las peculiaridades del medio, como, en algunos países, por razones exactamente opuestas. Pero, en cualquier caso, la radiotelevisión se aparta, con pocas excepciones, de lo que era y ha seguido siendo característica de la libertad de prensa: la libre iniciativa privada. Y el hecho de que tenga un relevante papel en la formación de la O. P. es una de las razones determinantes de la transformación jurídica de este medio. 
Nuestro T. C. parece admitir la constitucionalidad de la calificación que el legislador hace de la radiotelevisión como servicio público. Pero también se cuida de establecer la obligación que el legislador tiene, en caso de regular la gestión indirecta del servicio, de respetar los principios de libertad, igualdad y pluralismo. Estos principios pueden ser el resultado de las relaciones del conjunto de los medios (pluralismo externo), o pueden ser inherentes a cada uno de ellos (pluralismo interno), pero de una u otra forma habrán de inspirar necesariamente la regulación jurídica de la comunicación pública para que el proceso democrático no quede falseado.

El alcance de los derechos y libertades del artículo $20 \mathrm{CE}$ vuelve a ser planteado por el T. C. con ocasión de un recurso de amparo en el que se reivindicaba la prevalencia de estos derechos frente a la lesión que su ejercicio puede provocar en el honor de otras personas. Se trata de la STC 104/1986, de 17 de julio. El T. C. otorga el amparo argumentado que si bien el derecho al honor es un derecho fundamental, los derechos del artículo 20 CE son más que eso. Citando las sentencias 12/1982 y 6/1981, el tribunal aduce que significan también «el reconocimiento y la garantía de una institución política fundamental, que es la opinión pública libre, indisolublemente ligada con el pluralismo político que es un valor fundamental y un requisito del funcionamiento del Estado democrático». El hecho de que el artículo 20 de la Constitución garantiza el «mantenimiento de una comunicación pública libre» otorga a las libertades protegidas por ese artículo «una valoración que trasciende a la que es común y propia de todos los derechos fundamentales» (F. J. 5. $\left.{ }^{\circ}\right)^{3}$.

Pero esta valoración que trasciende la simple consideración de la libertad de expresión e información como un derecho fundamental no implica que, cuando se haya de ejercer a través de la radiodifusión o la televisión, ese derecho deba transformarse forzosamente en un servicio público de titularidad estatal. La alternativa derecho

${ }^{3}$ Se puede rastrear este argumento a lo largo de una jurisprudencia constante que, sin embargo, no resuelve todos los casos concretos planteados ante el tribunal en favor de la libertad de comunicación. Cuando las opiniones o la información entran en conflicto con otros derechos subjetivos, es precisa una ponderación casuística, en la que el interés general en la libre formación de la opinión pública debe prevalecer sobre el derecho subjetivo. Pero ello no significa que la libertad de expresión e información carezca de límites. Sobre el tema de los límites, A. Aguilera Fernández, La libertad de expresión del ciudadano y la libertad de prensa o información (Posibilidades y límites constitucionales), Granada, 1990; C. Carmona Salgado, Libertad de expresión e información y sus límites, Madrid, 1991; Marc Carillo, Los límites a la libertad de prensa en la Constitución española de 1978, Barcelona, 1987; R. Rebollo Vargas, Aproximación a la jurisprudencia constitucional: libertad de expresión e información y límites penales, Madrid, 1992. 
subjetivo - servicio público es objeto en la actualidad de un vivo debate, sobre todo en el ámbito de la doctrina administrativista. La diferencia es manifiesta. Desde el punto de vista teórico, la declaración de servicio público transforma el derecho fundamental inherente al individuo (que puede, desde luego, ser restringido con las limitaciones que se consideren pertinentes en orden a salvaguardar el pluralismo) en el derecho concedido por la Administración a gestionar una actividad cuyo titular es el Estado. Y, desde el punto de vista práctico, la declaración de servicio público escamotea el ejercicio inmediato del derecho por los particulares y lo hace depender de la voluntad política del Gobierno, que puede regularlo o aplazarlo indefinidamente, como es el caso hasta ahora de la modalidad de televisión de ámbito local ${ }^{4}$.

A pesar de que la argumentación del T. C. parece confirmar la admisibilidad de la declaración de servicio público para la radio y la televisión, la cuestión sigue abierta. Como el mismo T. C. ha afirmado en otra ocasión, concretamente en la sentencia 106/1986, de 24 de julio, hasta ese momento aún no se había pronunciado de una manera expresa y definitiva acerca de la validez del precepto del artículo 1.2 del Estatuto de RTV, ya que ninguno de los procesos constitucionales iniciados en virtud de un recurso de amparo «tuvo como objeto expreso y directo el control de dicho precepto» (E J. 2. ${ }^{\circ}$ ). El T. C. sigue sin pronunciarse frontalmente sobre la validez de este artículo, como tampoco lo ha hecho sobre el precepto correspondiente de la Ley de Ordenación de las Telecomunicaciones, de 8 de diciembre de 1987, que en su artículo 2.1 establece que «las telecomunicaciones tienen la consideración de servicios esenciales de titularidad estatal reservados al sector público».

Aunque ya no se dan las condiciones tecnológicas y económicas que condicionaron inicialmente la reserva al Estado de la radio y la televisión, sí siguen existiendo las condiciones sociológicas. Es, efectivamente, la profunda incidencia que sobre la cultura, la política, las actitudes y el modo de vida en general tienen la radio y la televisión, sobre todo esta última, lo que hace que se siga defendiendo su consideración como servicio público. En esto se basa la sentencia 206/1990, de 13 de diciembre, en la que el T. C. desestima varios

${ }^{4}$ Sobre la alternativa servicio público - derecho subjetivo se pueden ver más amplias referencias en D. Cuadra y M. Saavedra: «Crisis del Estado social y política institucional alternativa: los medios de comunicación de masas», en M. Monereo (coord.), Perspectivas del socialismo hoy, vol. I, Madrid, 1992, págs. 171 y ss.: pero sobre todo Fr. J. Bastida, La libertad de antena. El derecho a crear televisión, Barcelona, 1990, y C. Chinchilla, La radiotelevisión como servicio públicos esencial, Madrid, 1968. 
recursos de amparo contra determinadas resoluciones administrativas que denegaron la atribución de frecuencias y potencias de televisión y radio de alcance estrictamente local, y contra las sentencias que las confirmaron. Sus argumentos sobre el fondo de la cuestión son similares a los que ya conocemos, repitiendo sobre todo los que ya manifestó el tribunal en la sentencia 12/1982, de 31 de marzo.

No es esta la ocasión para entrar en el debate en torno a la calificación de la televisión como servicio público. De todas formas, también aquellos que, desde la doctrina jurídica, no se oponen a la calificación de la actividad radiotelevisiva como servicio público, recurren a la noción de O.P.L., en consonancia con la jurisprudencia constitucional, para tachar a nuestro sistema de televisión como gravemente deficiente desde el punto de vista constitucional $^{5}$. Aun admitiendo que la declaración de servicio público para la televisión sea constitucionalmente legítima, no parece que la organización jurídica de la televisión en nuestro país cumpla las condiciones necesarias para la formación de una O.P.L. A pesar de la Ley de Televisión Privada, de 3 de mayo de 1988, nuestro sistema jurídico de televisión está lastrado por una fuerte dependencia de la Administración, por su insuficiente pluralismo y por su absoluta dependencia del mercado de la publicidad, lo cual, como veremos después, es uno de los más graves obstáculos para esa libre formación de la O.P. que el T.C. dice ser el objetivo de la regulación jurídica del medio.

\section{La opinión pública libre y la legitimidad democrática}

Dejando a un lado el enjuiciamiento, desde el punto de vista constitucional, del sistema de televisión en nuestro país, quisiera referirme a continuación al porqué del potencial legitimador de la O.P.L., a las razones por las cuales la jurisprudencia constitucional basa en ella sus propuestas de legitimidad y crítica normativas. No es tan evidente

${ }^{5}$ C. Chinchilla Marín, «El servicio público, ¿una amenaza o una garantía para los derechos fundamentales? Reflexiones sobre el caso de la televisión», en S. Martín- Retortillo (coord.), Estudios sobre la Constitución española. Homenaje al Profesor Eduardo García de Enterría, vol. II: De los derechos y deberes fundamentales, Madrid, 1991, págs, 943 y ss.; J. Esteve Pardo, «Servicio público de televisión y garantía de la institución de la opinión pública libre», en Revista de Administración Pública, n. ${ }^{\circ}$ 123, sep-dic. 1990, págs. 185 y ss. Yo mismo he manifestado algunas dudas en otras ocasiones sobre la constitucionalidad de las leyes que rigen nuestra televisión. Así, en «La libertad de expresión e información y el problema de la televisión privada en nuestro ordenamiento jurídico», en Anuario de Filosofía del Derecho, N.E., T. I., 1984, págs. 219 y ss.; y en D. Cuadra y M. Saavedra, «Crisis del Estado social...», cit. 
que, ni siquiera en una sociedad democrática, la O.P. posea esa capacidad legitimadora que la hace convertirse en punto de referencia del ordenamiento jurídico-constitucional del Estado. No es tan evidente después de todas las experiencias que poseemos a estas alturas de la historia de las sociedades de «capitalismo industrial avanzado», por utilizar una expresión de uso frecuente. Los embates descalificadores que ha sufrido la O.P en este tipo de sociedades la han dejado en una situación problemática, que invita a cuestionar su potencial normativo y crítico.

El sentido y la valoración de la O.P. es algo controvertido. No es mi propósito ahondar en la teoría de este concepto. Han sido muchos y variados los planteamientos que han abordado el estudio del fenómeno al que alude la expresión, y muchas las definiciones que han intentado expresar sintéticamente su significado ${ }^{6}$. Doy por supuesto que en el lenguaje jurídico se utiliza sin demasiada precisión, recogiendo el uso ordinario del término. En ese sentido podríamos decir que alude a una forma de pensar, compartida por gran parte de los miembros de una sociedad, que incluye pretensiones normativas sobre asuntos socialmente relevantes, y que surge como resultado de un proceso de discusión en ámbitos y canales públicos. No es una magnitud homogénea, de tal manera que no podemos hablar de una única O.P., pero esto no le resta nada a su carácter representativo.

Entre las funciones de la O.P. figura en un primer plano la de actuar como instancia de legitimación política, y de ese supuesto partimos también aquí ${ }^{7}$. La dependencia del poder respecto a la opinión de aquellos que están sujetos a él se ha reconocido al menos desde Maquiavelo, es decir, desde antes de que, con los fisiócratas, se produjese una primera elaboración teórica del concepto.

Pero el adjetivo libre añade a la noción de O.P. una pretensión de autenticidad legitimadora. Ya no estaríamos en presencia de una mera función social de «legitimación», sino de una función ética de «legitimidad». El control y la influencia que una O.P. libremente

${ }^{6}$ Como muestra de esa variedad, véase el documentado estudio de C. Montón Arribas, La opinión pública. Teorías, concepto y métodos, Madrid, 1987. Un reciente intento de aclaración conceptual del término y de determinación de su alcance normativo en el Estado democrático, en Ruth Zimmerling: «Öffentliche Meinung. Öffentlichkeit und repräsentative Demokratie», en W. Krawietzy G. H. von Wright (eds.), Öffentliche oder private Moral? Festschrift für E. Garzón Valdés, Berlín. 1992, págs. 259 y ss.

${ }^{7}$ V. Rovigatti, Lecciones sobre la ciencia de la opinión pública, Quito, 1981, págs. 161 y ss.; E. Noelle-Neumann insiste también en la función de integración social que tiene la O.P.: Öffentliche Meinung. Die Entdeckung der Schweigespirale, Francfort/Berlín, 1989; «Public Opinion and the Classical Tradition: A Re-evaluation», en Public Opinion Quarterlv, 1979, págs. 143 y ss. 
formada ejerce sobre el poder puede pretender calidades normativas porque equivale a una forma de realizar la democracia. Como el Parlamento, y junto a él, tiene una función representativa. Según el paradigma democrático de legitimidad de los primeros liberales, a través de la O.P. se expresa permanentemente la soberanía popular. A través de la O.P. libremente formada, se entiende, es decir, como resultado de las libertades de opinión, de expresión y de prensa. Para la ideología democrático-liberal la O.P. es una instancia crítica y reflexiva que se forma mediante el razonamiento público que ejercen las personas privadas sobre los asuntos de interés general ${ }^{8}$. Libertad de expresión, racionalidad, O.P. y democracia están esencialmente vinculadas para una gran parte de la tradición liberal. En su lucha contra el despotismo, los liberales acentuaron las virtudes racionalizadoras de la discusión pública, y reclamaron para la O.P. libremente formada la capacidad de reflejar la verdad política en lo que atañe a los asuntos de gobierno. En Bentham, y también en Kant, encontramos estos motivos en su defensa de la libre y pública discusión. La libertad de expresión tendía a producir un O.P. valorada positivamente ${ }^{9}$.

Es verdad que, posteriormente, el liberalismo también ha vinculado la libertad de prensa a una O.P. valorada negativamente. También ha insistido en la necesidad de libertad de expresión y de prensa para oponerse a las verdades establecidas y denunciar errores, para criticar las convenciones que oprimen al individuo y disolver los prejuicios firmemente arraigados, es decir, para sacudirse el «yugo de la O.P.» (J. S. Mill, Tocqueville). De una O.P. que se percibe, ya no como un medio de racionalización del poder, sino como vehículo de la tiranía de una mayoría irreflexiva y susceptible de manipulación. Pero la insistencia en la necesidad de la crítica pública implica el reconocimiento del poder de esta última (de la crítica) para hallar la verdad, o al menos una nueva aproximación a la verdad, que sea capaz de fertilizar las opiniones y lograr puntos de vista que puedan ser compartidos. Un liberal de nuestros días, como K. Popper, comparte con Mill los mismos recelos ante la O.P. y el mismo optimismo ante las posibilidades racionalizadoras del debate público:

«Esa entidad intangible y vaga llamada opinión pública a veces revela una sagacidad sin rebuscamiento, o más a menudo, una sensibilidad moral superior a la del equipo gobernante. Sin embargo, constituye un peligro para la libertad, si no está

${ }^{8}$ Véase J. Habermas, Historia y crítica de la opinión pública, Barcelona, 1981.

${ }^{9}$ Ver M. Saavedra, La libertad de expresión en el Estado de derecho. Entre la utopía y la realidad, Barcelona, 1987. 
moderada por una fuerte tradición liberal. Es peligrosa como árbitro del gusto e inaceptable como árbitro de la verdad. Pero a veces puede asumir el papel de un ilustrado árbitro de la justicia (...). Debe distinguirse la opinión pública de la publicidad de la discusión libre y crítica que es (o debería ser) la norma en la ciencia, y que incluye la discusión de problemas de justicia y otros temas morales. La opinión pública recibe la influencia de las discusiones de este tipo, pero no es el resultado de ellas, ni está bajo su control. Su influencia benéfica será tanto mayor cuanto más honestas, simples y claras sean tales discusiones» ${ }^{10}$.

Esta distinción entre O.P. y publicidad debe ser retenida como una de las claves que puede ayudar a plantear correctamente el problema de la capacidad legitimadora de la O.P. Efectivamente, un planteamiento correcto confiere legitimidad, en primer lugar, a las instituciones de una publicidad crítica, entre las que se encuentran fundamentalmente las garantías jurídicas de la libertad de expresión, de información y de prensa. El potencial legitimador de la O.P. se deriva precisamente de la existencia de una publicidad activa, que permite el intercambio de información, la crítica mutua y el debate argumentativo ${ }^{11}$.

Esto es coherente con el sentido procedimental de la democracia, e incluso con el sentido comunicativo-racional de la legitimidad normativa. La democracia política es el conjunto de condiciones cuyo significado es hacer posible el surgimiento, bajo condiciones limitadas, de un acuerdo razonado sobre pautas de acción colectiva. Aun cuando ese acuerdo no se logre en la práctica, se presupone como objeto intencional de una discusión a base de argumentos. La democracia obtiene la legitimidad por su carácter deliberativo ${ }^{12}$. Incluso aunque se entienda la democracia más bien como estructura que hace posible el disentimiento, como instrumento de control y como medio

${ }^{10} \mathrm{~K}$. Popper, «La opinión pública y los principios liberales», en Id: Conjeturas y refutaciones, Barcelona, 1983, págs. 416 y ss., pág. 423.

${ }^{11}$ Esta distinción entre O.P. y publicidad se corresponde, por lo demás con la distinción que entre ambos conceptos puede trazarse desde un punto de vista sociológico. La publicidad -o esfera pública- sería un sistema comunicativo que actúa como intermediario entre el sistema político, los ciudadanos y otros subsistemas sociales, que selecciona, elabora y sintetiza información, y que produce opinión pública. Véase J. Gerhards y F. Neidhardt, Strukturen und Funktionen moderner Öfentlichkeit. Fragestellungen und Ansätze, Berlín, 1990.

${ }^{12}$ En el Prólogo a la última edición de Strukturwandel der Öffentlichkeit (Francfort, 1990) Habermas conecta en este sentido las estructuras de la publicidad con la ética del discurso (págs. 38 y ss.). También en Faktizität und Geltung. Beiträge zur Diskurstheorie des Rechts und des demokratischen Rechtsstaats, Francfort, 1992, págs. 349 y ss. 
para manifestar y reivindicar la oposición y el desacuerdo ${ }^{13}$, ese carácter deliberativo es el que le sigue confiriendo la legitimidad.

Pero la existencia de una publicidad activa no garantiza que la O.P. sea el resultado de ese debate público y libre. Antes bien ésta puede escapar a su control, y esto es lo que ha originado el escepticismo sobre su capacidad legitimadora.

Las críticas reiteradas de que ha sido objeto el concepto de O.P. han denunciado desde distintos planteamientos su proclividad a dejarse influir por impulsos instintivos, estereotipos y prejuicios fuertemente condicionados por las fuerzas y factores operantes en una sociedad de masas. No quiero abundar en esas críticas, que han desvalorizado el potencial racionalizador y legitimador de la O.P. Desde Hegel hasta los estudios actuales sobre el funcionamiento y los efectos de los medios de comunicación de masas, puede ponerse en duda, por unas u otras razones, que la O.P. sea el resultado de un debate racional. Esta O.P. no sería más que una ficción de la que sin embargo sigue alimentándose el discurso jurídico-constitucional del Estado de derecho ${ }^{14}$.

Si el discurso jurídico sigue alimentándose de esta noción normativa de O.P.L. es precisamente en el sentido democrático liberal originario de representar el parecer de la sociedad como resultado del funcionamiento sin trabas de la publicidad. La O.P.L. no es un hecho, es una aspiración. Una aspiración que proyecta determinados condicionamientos regulativos sobre las instituciones sociales que tienen más influencia objetiva en su formación: los medios de comunicación de masas.

¿Pueden los medios de masas cumplir esa aspiración? ¿Pueden actualizar el potencial democrático expresado en su función de contribuir a la formación de una O.P.L.?

En su «Teoría de la acción comunicativa» ${ }^{15}$ Habermas habla de la ambivalencia de los medios, de su doble potencial, autoritario y emancipatorio, de las contradicciones a las que están sometidos y que hacen las comunicaciones que transcurren por ellos «nunca pueden quedar fiablemente blindadas contra la posibilidad de ser contradichas por actores capaces de responder autónomamente de sus propios actos» ${ }^{16}$. Ya en Historia y crítica de la opinión pública, tras el estudio histórico-crítico que realizaba en esa obra de la degradación de la O.P. debido a las transformaciones sufridas por el ámbito de la publicidad,

${ }^{13}$ J. Keane, The Media and Democracy, Cambridge, 1991: también Democracia y sociedad civil, Madrid, 1992.

${ }^{14}$ J. Habermas, Historia y crítica de la opinión pública, cit., pág. 262. También C. Montón, La opinión pública, cit.. págs. 27 y ss.

${ }^{15}$ Vol. II, págs. 552 y ss.

${ }^{16}$ Ibíd., pág. 553. 
dejaba ver la posibilidad de superar la dinámica comunicativa que había hecho del público una masa aclamadora y acrítica ${ }^{17}$.

En el Prólogo a la edición de 1990 de esa misma obra se pronuncia de una manera mucho más expresa sobre esa posibilidad, considerando sus razonamientos primitivos sobre la capacidad de resistencia y el potencial crítico del público de masas como demasiado pesimistas. Según él, a las funciones integradoras de los medios se contrapone un proceso de comunicación pública «que se regenera espontáneamente de las fuentes del mundo de la vida» ${ }^{18}$, un proceso de comunicación autónomo, que discurre horizontalmente, y que tiene lugar en distintos ámbitos de la sociedad civil, sobre todo en instituciones y por instituciones de carácter asociativo, lejos del sistema administrativo. Asociaciones culturales, clubs de debates, foros ciudadanos, academias, Iglesias, medios independientes, organizaciones alternativas, etc., formarían la trama de tales instituciones. Habermas plantea, no obstante, la pregunta, «que no puede ser contestada sin un considerable despliegue de carácter empírico: si y en qué medida una publicidad dominada por los medios de masas permite a los elementos que sostienen la sociedad civil competir prometedoramente con el poder mediático de los invasores políticos y económicos, y por tanto modificar el espectro de los valores, temas y razones canalizados mediante influencias externas, superar sus límites de manera innovativa y filtrarlos críticamente» ${ }^{19}$.

Desde la teoría de los medios de comunicación de masas se han venido realizando propuestas organizativas para desarrollar un modelo de comunicación audiovisual alternativo a los tradicionalmente existentes, dominados por las instituciones burocrático-administrativas o por el mercado. Se trataría de aprovechar las posibilidades abiertas por la ampliación de las disponibilidades tecnológicas, superando las barreras físicas e incluso económicas que han impedido el pluralismo en el ámbito de la comunicación pública. Tal modelo democrático-participativo de comunicación se traduciría en una red pluralista y descentralizada de medios no sujetos al mercado, por la que circularían sin restricciones la información y las opiniones que no encuentran eco suficiente en los canales clásicos, ampliando el proceso de formación de la opinión y ganando espacios para una regeneración democrática de la publicidad ${ }^{20}$.

Es impensable que tal modelo pueda funcionar como una alternativa a los grandes medios de comunicación, centralizados y dirigidos

${ }^{17}$ Historia y crítica de la opinión pública, cit.. págs. 257 y ss.

${ }^{18}$ Strukurwandel der Öffentlichkeit, cit., pág. 28.

${ }^{19}$ Ibíd., pág. 17.

${ }^{20} \mathrm{D}$. McQuail, Introducción a la teoría de la comunicación de masas. Barcelona, 1985, págs. 118 y ss. M. Saavedra, La libertad de expresión en el 
a grandes masas de audiencia. Es más realista pensar que ocuparía un lugar secundario, en los intersticios o en los márgenes del sistema dominante, representado por las cadenas de radio y televisión estatales y regionales, y por los periódicos de amplia difusión. Pero con los grandes medios, públicos o privados, seguiríamos contando con los problemas burocráticos y comerciales que limitan el pluralismo comunicativo.

Otra posibilidad es orientar democráticamente la comunicación a través del modelo dominante, es decir, conseguir que los medios, en su conjunto, se hagan portavoces también de los intereses y expectativas de las minorías, y de los hechos y acontecimientos que les afectan, y que la información que difunden no adolezca de esa parcialidad característica que es consecuencia de la sumisión de los medios a la Administración o al mercado. Esta posibilidad es admitida por Habermas en Faktizität und Geltung, donde vuelve a defender el potencial crítico y democrático de la publicidad, no sin antes señalar las sombras que sobre ese ámbito arrojan unos medios sesgados por las fuerzas políticas y sociales dominantes $^{21}$.

Ahora bien, la posibilidad de recuperar los medios para una publicidad legitimadora depende de que sean apartados los obstáculos que esos mismos medios oponen a una comunicación auténticamente democrática, y por tanto, a la libre formación de la opinión.

\section{Los obstáculos que impiden una libre formación de la opinión pública a través de los medios de comunicación de masas}

Los medios actúan como vehículos que transportan la información, que sostienen la comunicación, que median entre los participantes en el proceso de discusión pública, pero también hacen algo más importante. Los medios actúan como canales autónomos de información y de argumentación, es decir, no como simples portavoces, sino como instituciones que poseen su propia legalidad y que condicionan con su propia dinámica el debate del que resulta la O.P.

Tradicionalmente se ha pensado que los obstáculos a la libre formación de la opinión proceden del contexto regulativo de los medios: la censura, el monopolio y el mercado. Pero cada vez se hace más

Estado de derecho, cit., págs. 140 y ss. Sobre el potencial democrático de este sistema de comunicación, recientemente, J. Keane, The Media and Democracy, Cambridge, 1991; también «La democracia y los medios de comunicación», en RICS (UNESCO), 129, 1991, págs. 549 y ss.

${ }^{21}$ Faktizität und Geltung, cit., págs. 435 y ss. 
evidente que también proceden de los mismos medios, que, en combinación con un determinado entorno sociocultural, impiden o fomentan un determinado tipo de discurso, de información, o de aproximación a la realidad, que puede poner en cuestión la integridad de la O.P. resultante.

Los obstáculos a los que me acabo de referir están graduados de mayor a menor evidencia, pero no de mayor a menor eficacia. La censura y el monopolio han constituido el blanco de los ataques clásicos de los defensores de la libertad de expresión y de prensa. La primera batalla en favor de la libertad de prensa se dirige contra la censura mantenida por el despotismo del antiguo régimen. Ganada la batalla contra la censura, la amenaza contra la libertad va a proceder, ya en tiempos más recientes, de la concentración producida por la dinámica de los derechos de la propiedad y de la libre iniciativa económica. Contra ella se dirigen, con más o menos éxito, las legislaciones de los países democráticos, adoptando diversas medidas que favorecen la pluralidad de fuentes de información o que impiden el monopolio económico y publícístico.

El mercado empieza a denunciarse como un obstáculo para la libre formación de la O.P. desde los mismos albores de la prensa comercial. No sólo porque conduce a la concentración, sino porque proyecta sus propios intereses, específicos, sobre la dinámica informativa y cultural de la que resulta la O.P., restringiendo, como la censura y el monopolio, la variedad de mensajes que tienen acceso a la publicidad.

Con todo, lo que creo más importante es que la misma forma de ejercer la comunicación a través de los medios es restrictiva. Y esto con independencia (relativa) de la forma de financiación del medio correspondiente. Y es restrictiva para la formación de una OPL. que para ser tal necesita tener acceso a una información lo más completa y objetiva posible acerca de la realidad. Sin embargo, la información que suministran los medios es, de una manera específica, incompleta y subjetiva.

No es reprochable para la constitución democrática de la publicidad la incompletud y subjetividad de la información ofrecida por los medios individualmente considerados. No es muy problemático el hecho de que un periódico seleccione, o resalte, de entre los datos que ofrece la realidad, aquellos que le parece que poseen un mayor valor informativo. Ni es tampoco problemático que un medio o un periodista deje traslucir sus propias preferencias políticas o ideológicas a través de la información que transmite ${ }^{22}$. Esto no es forzosamente negativo para la formación de la O.P., dando por supuesta la existencia

${ }^{22}$ H. M. Kepplinger habla de una «gestión de los acontecimientos» por parte de la prensa, y muestra, utilizando los métodos propios de las ciencias sociales empíricas, la parcialidad típica del trabajo periodístico, a la que denomina «actualización 
de una pluralidad de medios con distintas tendencias políticas e ideológicas. Si el individuo cuenta con un acceso a distintas fuentes de información, podrá obtener un panorama más o menos completo y objetivo de la realidad ${ }^{23}$.

Tampoco es problemático el hecho de que los medios «construyan» la realidad. Es decir, tampoco es problemático si no se pretende que el conocimiento, o el lenguaje, sea una representación objetiva de la realidad. En la actualidad nadie sostiene esta pretensión, y, como todo el mundo sabe, las distintas teorías del conocimiento postpositivistas han problematizado en uno $\mathrm{u}$ otro sentido la relación sujeto-objeto, para hacer partícipe al primero de la constitución del segundo. La realidad no es accesible si no es a través de alguna representación de la misma, y precisamente a través de los medios se nos ofrece una tal representación.

Los medios transmiten una noción de la realidad en forma de noticias, comentarios, informes, etc., de un lado, y tomas de posición, críticas, opiniones, etc., de otro. Con ser esto último importante, aún lo es más lo primero. Así, se ha dicho que los medios tienen una función de «agenda-setting», de tal manera que la realidad que llega a ser objeto de la O.P. es la que los medios transmiten, y en la forma en la que éstos la transmiten. Ya en 1963 pudo decir Bernard Cohen que «(...) la prensa es significativamente algo más que un proveedor de información y de opinión. Puede que no tenga éxito muchas veces en decirle a la gente qué tiene que pensar, pero es tremendamente eficaz en decirle a los lectores sobre qué tienen que pensar» ${ }^{24}$. Los medios son selectivos, como también lo es el historiador o el sociólogo que

instrumental». Ver Ereignismanagement. Wirklichkeit und Massenmedien, Zurich, 1992; también H. M. Kepplinger y otros, «Instrumentelle Aktualisierung. Grundlagen einer Theorie publizistischer Konflikte», en M. Kaase / W. Schulz (eds.). Massenkommunikation. Theorien, Methoden, Befunde, Opladen 1989, págs. 199 y ss.

${ }^{23}$ Sí es reprochable, evidentemente, que el periodista, en el ejercicio de su actividad informativa, no cumpla las reglas de deontología profesional. Una de las más importantes es la que obliga a presentar separadamente la información y las opiniones, exigiendo para la información que ésta no sea manipulada intencionalmente para engañar al público. Ello viene exigido por la responsabilidad que debe guiar el ejercicio de la libertad de expresión por los profesionales, en virtud del derecho a la información que tiene la audiencia. Pero no siempre se hace así. Sobre el tema, L. Erbing, «Nachrichten zwischen Professionalität und Manipulation. Journalistische Berufsnormen und politische Kultur», en M. Kaase / W. Schulz (eds.), Massenkommunikation, cit., págs. 301 y ss.

${ }^{24}$ The Press and Foreign Policy, Princeton, 1963, pág. 13. Sobre la función de tematización o «agenda-setting» de los medios hay una larga serie de estudios teóricos y empíricos a partir del análisis de M. McCombs, y D. Shaw sobre las elecciones presidenciales norteamericanas de 1968. Ver M. McCombs y D. Shaw, "The Agenda-Setting Function of Mass Media», en Public Opinion Quarterly, vol. 36, 1972, págs. 176 y ss.; D. Weaber y otros, Media Agenda-Setting in a Presidential Election 
intentan transcribir una noción fidedigna de la realidad ${ }^{25}$. Más aún, también como en el caso del historiador y el sociólogo, la selectividad de los medios es constitutiva en el sentido de que se produce mediante la aplicación a un objeto externo de una serie de categorías, experiencias preconstituidas y reglas de la práctica profesional, cuya interacción da lugar a la realidad correspondiente ${ }^{26}$.

Lo verdaderamente preocupante es que esa construcción de la realidad adolece de una parcialidad específica, que no es políticamente neutra y que contrasta con la que se puede obtener a través de otros medios. Estos otros medios pueden ser informes estadísticos, observaciones directas de los mismos acontecimientos, documentos oficiales, o incluso estudios históricos. Comparativamente, la imagen massmediática de la realidad posee unas características peculiares, cuyas repercusiones sobre la conciencia individual, la O.P. y el juego político son innegables.

Las características de la imagen de la realidad ofrecida por los medios han llamado la atención de sociólogos y teóricos de la comunicación desde fechas muy tempranas. Ya Walter Lippman, en 1992, advertía acerca de la simplificación de los acontecimientos realizada por las noticias de la prensa. Según él, debido a la enorme presión bajo la que trabaja, con limitaciones de tiempo y en competencia con otros periódicos, y movido por el objetivo de suscitar el interés de los lectores, el editor de prensa tiene que recurrir a la estandarización, al

Issues, Images, Interest, Nueva York, 1981; H.-J. Weiss, «Öffentliche Streitfragen und Massenmediale Argumentationstrukturen. Ein Ansatz zur Analyse der inhaltlichen Dimension im Agenda Setting-Prozess», en M. Kaase / W. Schulz (eds.), Massenkommunikation, cit., págs. 473 y ss.; recientemente, de nuevo M. McCombs y D. Shaw, «The Evolution of Agenda-Setting Research: Twenty-Five Years in the Marketplace of Ideas», en Journal of Communication, 43, 1993. n. ${ }^{\circ}$ 2. págs. 58 y ss.

${ }^{25}$ Sobre el carácter selectivo del proceso de comunicación escribe N. Luhmann en «Veränderungen im System gesellschaftlicher Kommunikation und die Massenmedien», en Oskar Schatz (ed.): Die elektronische Revolution. Wie gefährlich sind die Massenmedien?, Graz, 1975, págs. 13 y ss. Para él. la O.P. hay que entenderla precisamente desde ese punto de vista: como una estructura que determina los temas sobre los que se articula el proceso de comunión política. Lo que importa de la O.P. no es tanto su carácter de opinión (su discutibilidad, su racionalidad, su capacidad de consenso, su justificabilidad pública), cuanto su función selectiva respecto a los temas discutibles. Ver «Öffentliche Meinung», en Politische Planung, Opladen, 1971, págs. 9 y ss.

${ }^{26}$ Este es, aproximadamente, el sentido que Kuhn ha dado a la noción de paradigma y que tanta fortuna ha tenido en la teoría de la ciencia. De una manera similar, por lo que respecta a los medios, Mark Fishman, Manufacturing the News, Austin, 1980. Roger Fowler mantiene esta misma tesis desde una perspectiva sociolingüística, Language in the News. Discourse and Ideology in the Press, Londres, 1991. 
empleo de juicios rutinarios y al abandono de toda sutileza. La estilización aumenta el valor noticioso del acontecimiento. El concepto de estereotipo, introducido por él en las ciencias sociales, le sirve para caracterizar la forma de presentar la realidad que ofrece la prensa. El estereotipo es una simplificación de la percepción social determinada por prejuicios, mediante la cual se consigue llamar la atención de los lectores, suscitando una rápida orientación y provocando un sentimiento de identificación personal ${ }^{27}$.

Posteriormente se comenzó a estudiar sistemáticamente el tipo de acontecimientos que eran recogidos por los medios narrados como noticias, cuáles eran sus características y qué factores influían en su selección. Si tenemos en cuenta que la tarea más importante de los medios es la ya mencionada de fijación de la agenda, es fundamental conocer los mecanismos por los cuales se selecciona y se da forma a la información de actualidad. Esta fue la intención de una serie de investigadores que, desde los años cincuenta, intentaron desarrollar la hipótesis del periodista como «Gate-keeper» que controla el acceso de la realidad a la calidad de noticia ${ }^{28}$. Con insuficiencias, contradicciones y nuevas aportaciones de otras corrientes de investigación, los estudios sobre la selección de noticias, tanto en EE.UU. como en Europa, han establecido y sometido a contrastaciones empíricas algunos criterios (o factores noticiosos) que aparecen como relevantes a fin de asignar a los acontecimientos el «valor noticioso» necesario para aparecer en los medios de información ${ }^{29}$. Cuando más marcados aparecen estos factores, o cuantos más de ellos coinciden en un determinado acontecimiento, mayor es la probabilidad de que dicho acontecimiento se convierta en noticia. Igualmente, también se recurre a ellos, acentuándolos o resaltándolos en el mensaje informativo, o reconstruyendo el mensaje en función de tales factores, para dotar de valor noticioso a un determinado acontecimiento ${ }^{30}$. Entre estos factores destacan la curiosidad (posibilidad de llamar la atención), el potencial

${ }^{27}$ W. Lippmann, Public Opinion, Nueva York, 1992, págs. 338 y ss.

${ }^{28}$ David M. White, «The 'Gatekeeper': A case Study in the Selection of News», en Journalism Quarterly, 27, 1950, págs. 383 y ss.

${ }^{29}$ Einar Östgaard, «Factors Influencing the Flow of New», en Journal of Peace Research, 2, 1965, págs. 39 y ss.; J. Galtung y M. H. Ruge, «The Structure of Foreign News», en Journal of Peace Research, 2, 1965, págs. 64 y ss.; W. Schulz, Die Konstruktion von Realität in den Nachrichtenmedien, Friburgo/Munich, 1976; Id.: «Massenmedien und Realität», en M. Kaase/W. Schulz (eds.), Massenkommunikation, cit., págs. 135 y ss.

${ }^{30}$ A esto obedece normalmente el éxito de ciertas campañas que, instrumentalizando tales factores, persiguen intereses políticos, económicos, corporativos, etc. A este procedimiento se ha referido especialmente H. M. Kepplinger, Ereignismanagement, cit.; también J. F. Staab, Nachrichtenwert-Theorie. Formale Struktur und empirischer Gehalt, Friburgo/Munich, 1990. 
emotivo, el etnocentrismo, el énfasis en lo negativo (conflicto, agresión, destrucción, etc.), la personalización de los acontecimientos, la concentración en personas y en naciones de élite, la sorpresa, etc.

En conjunto, hay una vasta literatura que confirma la distorsión y el desequilibrio que se producen debido a la acentuación de estos factores. Así, por ejemplo, es frecuente que los grupos minoritarios de la población aparezcan subrepresentados y estereotipados, que los crímenes violentos, el terrorismo y la corrupción aparezcan sobredimensionados, que la imagen de los personajes, especialmente de los personajes políticos, acapare la preocupación de los que ejercen la actividad informativa, que los informes científicos y técnicos reproducidos por los medios aparezcan muchas veces con importantes deficiencias e inexactitudes debido a motivaciones sensacionalistas, etc. ${ }^{31}$

Otros análisis teóricos han puesto de manifiesto cómo, desde un punto de vista formal, la información massmediática adopta una estructura que inhibe la percepción de procesos que transcurren bajo la superficie de los acontecimientos diarios. La información de actualidad, la noticia, posee una forma narrativa, orientada a comunicar aspectos concretos de la realidad. De esta manera, sólo proporciona una imagen caleidoscópica y fragmentada de los hechos. A través de ella es imposible obtener un conocimiento sistemático de la realidad. Su objetivo es aprehender el momento, captar la historia en sus detalles actuales, resaltar los contingentes, pero no proveer un marco en el que se vinculen los acontecimientos para lograr un conocimiento de la realidad en toda su complejidad ${ }^{32}$.

La organización institucional en la que se desarrolla el trabajo profesional de los informadores impone también unos condicionamientos

${ }^{31}$ B. Greenberg, «Minorities and the Mass Media», en J. Bryant y D. Zillmann (eds.), Perspectives on Media Effects, Hillsdale (N. J.), 1986, págs. 165 y ss.: K. Lang y G. E. Lang, Politics and Television, Chicago, 1968; Id., Politics and Television Re-viewed, Beverly Hills, 1984; Doris A. Graber, Crime News and the Public, Nueva York, 1980; W. B. Jaehnig y otros, «Reporting Crime and Fearing Crime in Three Communities», en Journal of Communication, 31, 1981, n. ${ }^{\circ}$ 1, págs. 88 y ss.; M. Cronholm y R. Sandell, «Scientific Information: A Review of Research», en Journal of Communication, 31, 1981, n. ${ }^{\circ}$ 2, págs. 85 y ss.; C. J. Glynn y A. R. Tims, «Sensationalism in Science Issues: A Case Study», en Journalism Quarterly, 59, 1982, págs. 126 y ss.; Sobre estos y otros testimonios, véase W. Schulz (eds.), Massenkommunikation, cit., págs. 135 y ss.

${ }^{32}$ Véase Robert E. Park, «News is not history, however, and its facts are not historical facts. News is not history because, for one thing among others, it deals, on the whole, with isolated events and does not seek to relate them to one another either in the form of causal or in the form of teleological sequences». («News as a Form of Knowledge», en Id., On Social Control and Collective Behaviour (ed. H. Turner), Chicago, 1967, págs. 33 y ss., pág. 39). También E. Barbara Phillips, «What is 
sobre su actividad. Los criterios de organización son selectivos. Así, por ejemplo, la necesidad de cubrir un espacio y un tiempo determinados, y no otros, proyecta «kantianamente» unas determinaciones que filtran los acontecimientos sobre los que se podría, en principio, elaborar una información. Actúan como una red que captura algunos elementos de la realidad, ignorando otros, que pasan desapercibidos.

En resumen, podríamos citar a N. Luhmann, el cual indica que la actualidad de los acontecimientos, el interés en conseguir la atención del receptor, y los condicionamientos propios de la organización, actúan como criterios sistémicos que gobiernan el proceso selectivo de la información, añadiendo que tales criterios actúan de manera distorsionante ${ }^{34}$. Con la televisión se agudizan estas características, primando la orientación hacia el entretenimiento y el énfasis en el espectáculo sobre las cualidades informativas propiamente dichas. La disparidad entre la complejidad del proceso político y su reflejo en los medios se incrementa en el caso de la televisión. En este medio la política queda especialmente simplificada y «despolitizada $\rangle^{35}$.

Todo esto nos permite concluir que la información massmediática, que es la base de la formación de la O.P., tiene unas características y unos condicionamientos que contradicen su valor informativo, tanto por la parcialidad o unilateralidad de sus contenidos típicos, como por la fragmentariedad y descontextualización de su estructura formal. Quedan excluidos de la publicidad toda una serie de temas que no se corresponden con las expectativas de la mayoría de la audiencia. Para que las minorías alcancen la resonancia necesaria en orden a influir en la formación de la O.P. con sus temas, intereses y preocupaciones, tendrían que utilizar otros resortes de la publicidad. Es decir, tendrían que hacerse oír en otros escenarios, desarrollando movimientos

News? Novelty without Change», en Journal of Communication, 26, 1976, n. ${ }^{\circ}$ 4. págs. 87 y ss. Y, recientemente, Allan Bell, The Language of News Media, Oxford, 1991, esp. págs. 147 y ss., sobre las características del lenguaje informativo.

${ }^{33}$ Ver Gaye Tuchman, Making News: a Study in the Construction of Reality, Nueva York, 1978; Herbert J. Gans, Decidibg What's News, Nueva York, 1979; Mark Fisxhman, Manufacturing the News, cit.

${ }^{34}$ N. Luhmann, «Veränderungen im System gesellschaftlicher Kommunikation und die Massenmedien», cit., pág. 24 y ss.

${ }^{35}$ Ver David L. Altheide, Creating Reality. How TV News Distorts Events, Beverlly Hills, 1974. Max Kaase, «Vernsehen, gesellschaftlicher Wandel und politischer Prozess», en M. Kaase/W. Schulz (eds.), Massenkommunikations, cit., págs. 97 y ss.; Frank E. Böckelmann(ed.), Medienmacht und Politik, Berlín, 1989. Sobre la simplificación que la televisión produce, en general, en los contenidos que transmite, ver Neil Postmann, Amusing Ourselves to Death. Public Discourse in the Age of Show Business, Nueva York, 1985. 
sociales, iniciativas ciudadanas, acciones de protesta, etc. Por esta vía es por donde J. Habermas intenta nuevamente recuperar el valor normativo de la O.P. Pero para lograr el éxito, según él, son necesarias determinadas condiciones sociales que definan una situación como crítica. El público tiene que sentirse afectado, a fin de que su atención se dirija a los mensajes correspondientes ${ }^{36}$.

No está claro, sin embargo, que los temas sobre los que el sector crítico del público llama la atención de los medios permanezcan incólumes al hacerse objeto de referencia de la comunicación de masas. Frecuentemente se produce una trivialización que actúa como una fórmula para la insensibilización y normalización de la O.P., en beneficio de la integración sistémica y de la reproducción del statu quo. Lo hemos visto con los símbolos de la protesta juvenil, la ecología, el feminismo... los medios procesan estos mensajes a su manera, despojándolos de su carácter antagonista, de su radicalidad, para convertirlos en objeto de consumo por unas masas fundamentalmente despolitizadas.

Si esto es así, ¿cómo podemos contestar entonces la pregunta sobre la capacidad legitimadora de la O.P.L.? Según nuestro T.C., la O.P.L. es una condición indispensable para dotar de contenido real los derechos y garantías que la Constitución consagra. Sin ella quedaría falseado el principio de legitimidad democrática. Pues bien, después de lo que hemos visto, se impone cierto escepticismo sobre la autenticidad del proceso democrático en las sociedades de los medios de masas. No es nueva la crítica del Estado democrático por insuficientemente democrático. El modo de funcionamiento de los medios aporta un aspecto más que merece ese mismo tipo de crítica.

Por otro lado, según nuestro T.C., la O.P.L. es la condición que permite hablar de una constitución jurídica legítima de los medios. En virtud de ella se permite una intervención del Estado tendente a regular su organización, limitando la iniciativa privada o impidiendo el ejercicio espontáneo del derecho a la libertad de expresión. De nuevo, después de lo que hemos visto, se impone cierto escepticismo sobre el grado en que los medios pueden alcanzar ese objetivo. Por muy perfecta que sea esa constitución jurídica, los medios tenderán inevitablemente, por su misma naturaleza, a producir una O.P. más o menos restringida.

${ }^{36}$ Faktizität und Geltung, cit., pág. 461. Es una lógica consecuencia de la prioridad de las «reglas de atención» sobre las «reglas de decisión» para la resolución de los problemas políticos, de las que habla N. Luhman en «Öffentliche Meinung». cit.. págs. 15 y ss. Sobre las estrategias de formación de la O.P. hablan también J. Gerhards y F. Neidhart, Strukturen und Funktionen moderner Öffentlichkeit, cit., págs. 37 y ss. 
Pero los medios no pueden dejar de ser medios, ni la democracia puede prescindir de ellos. Por eso hacen falta otros instrumentos que contrarresten sus efectos negativos y potencien sus efectos positivos para la formación de la O.P. El abanico de medidas que pueden contribuir a mejorar el producto de los medios, la información, es muy amplio. Desde luego, no se puede equiparar la prensa de prestigio con la prensa amarilla, los programas de televisión que podríamos llamar dignos con los subproductos a que nos tienen acostumbrados algunas cadenas comerciales. La crítica que he intentado realizar aquí ha prescindido conscientemente de estas distinciones. Para mejorar el producto de los medios se pueden utilizar resortes económicos y fiscales, por ejemplo, normas deontológicas y organizativas, normas que regulen el acceso y la financiación, etc.

Pero, dando por supuesto que todas estas normas desarrollen sus mejores efectos sobre la actividad de los medios, quedará siempre la inercia de dotar a la información de un carácter atractivo y seductor para el receptor potencial, con sus efectos distorsionantes. Frente a esto creo que se impone, como último recurso, la necesidad de educar a la audiencia. Y ello en dos sentidos. En primer lugar, en un sentido general. La parcialidad de la información de actualidad puede quedar compensada con la formación cultural del público. Un público entendido lee los periódicos de forma diferente. La formación cultural del receptor constituye el contexto capaz de dar sentido a las noticias. Ella es la que proporciona las claves explicativas que permiten entender «lo que pasa». En segundo lugar, en un sentido específico, es decir, en el uso y consumo de los medios. Dada la importancia que éstos tienen para la vida social, el público no puede ignorar su forma de funcionamiento, las necesidades a las que se ven sometidos los profesionales, los factores que dan lugar a la elaboración de la información, la dinámica de la producción de noticias, etc. Ya desde la escuela habría que inducir en el consumidor la mentalidad crítica necesaria para enfrentarse a la prensa y a la televisión de una manera menos pasiva e ingenua de lo que es habitual ${ }^{37}$. Tal vez así quedaríamos menos expuestos al poder de los profesionales y podríamos ser más dueños de nosotros mismos, más autónomos, que es, en definitiva, el presupuesto esencial y el objetivo final de la democracia.

${ }^{37}$ Como muestra de la importancia que está adquiriendo últimamente la conciencia de esta necesidad, véase el libro editado por la Fundación Bertelsman Medienkompetenz als Herausforderung an Schule und Bildung, Gütersloh, 1992, que recoge un simposio germano-norteamericano sobre el tema, con contribuciones de Ulrich Saxer, George Gerbner, Elihu Katz, Hertha Sturm, etc. 